\title{
El Chispazo y el proyecto modernizador. Un acercamiento a «En los trenes», de Juan de Arona ${ }^{1}$
}

\section{Néstor Saavedra Muñoz}

Universidad Nacional Mayor de San Marcos

¿No hay aquí pueblo? ¿Pueblo? Si a fe mía ¿Pues dónde se halla? Este pueblo Sober-asno y esta ejerciendo la sober-asnia

Juan de Arona

\section{RESUMEN}

La prensa decimonónica merece ser revalorada, en primer lugar, por el papel que cumplió dentro del proceso de formación del cuento moderno. Las revistas y periódicos de la época se constituyeron como un espacio de tránsito en el que las formas narrativas se debaten entre el artículo de costumbres, la tradición, la leyenda y el cuento propiamente dicho. Y en segundo lugar, la producción textual del periodo resulta valiosa en función de su interés por reflejar la realidad social inmediata y discutir en torno a sus problemáticas desde una perspectiva ideológica que busca el desarrollo de la nación.

El artículo se orienta, precisamente, hacia el estudio de este último punto a partir de la presentación y análisis de «En los trenes» ${ }^{2}$ de Juan de Arona, texto recogido del periódico El Chispazo (1891-1893). El relato de Arona cobra relevancia en la medida en que responde a una poética en la que el quehacer literario promueve el proyecto modernizador de la sociedad. En nuestra exégesis se pondrá especial énfasis en las estrategias discursivas mediante las cuales se valida al individuo burgués como ideal para la sociedad moderna, pues en él se encarnan la sensibilidad estética, el orden y el progreso.

1 Ponencia presentada en el Congreso Internacional Perú XIX, «Universos discursivos en la prensa peruana decimonónica», 8 de julio de 2008, en la Facultad de Letras y Ciencias Humanas de la Pontificia Universidad Católica del Perú.

2 El texto se adjunta al final del presente artículo. 


\section{PALABRAS CLAVE}

Juan de Arona, El Chispazo, modernización, alteridad, sujeto subalterno, sujeto burgués, procesos sociales decimonónicos, heterogeneidad cultural, modernidad inconclusa.

\section{ABSTRACT}

The nineteenth-century press deserves to be reassessed, first of all, for the role they fulfill in the process of the modern short stories formation. Magazines and newspapers of the time were formed as a transit space in which narrative forms are torn between the article by custom, tradition, legend and the story itself. Secondly, the textual production period is valuable in terms of their interest in the immediate social reality reflected upon and discuss their problems from an ideological perspective that seeks to develop the nation.

The article is geared precisely to study this last point from the presentation and analysis of «En los trenes» by Juan de Arona, picked up in the newspaper El Chispazo (1891-1893) text. Arona's story becomes relevant to the extent that it corresponds to a poetic in which the literary work promotes the modernizing project of society. In our exegesis special emphasis will be on the discursive strategies through which validates the bourgeois individual as ideal for modern society, for in it the aesthetic sensitivity, order and progress incarnate .

\section{KEY WORDS}

Juan de Arona, El Chispazo, modernization, otherness, subaltern subject, middle society subject, social process of thenineteenth-century, cultural heterogeneity, modernity unfinished.

\section{Apuntes sobre El Chispazo, de Juan de Arona}

A Pedro Paz Soldán y Unanue (1839-1895) lo conocemos por sus composiciones poéticas, narrativas, teatrales y ensayísticas. Sus datos biográficos no son del todo desconocidos para quienes se han ocupado de su obra. Realizó estudios en el Convictorio Carolino. Viajó por Europa y el Cercano Oriente entre 1859 y 1863 . Ejerció la docencia en el Colegio Guadalupe y en la Universidad de San Marcos. También estuvo relacionado con actividades políticas, pues fue diplomático y ministro en Argentina y Brasil. 
Incursionó en el campo periodístico colaborando en diversos diarios y revistas del periodo. Fue editor de La Saeta (1869), El Chispazo (1891-1893), entre otras publicaciones ${ }^{3}$.

El Chispazo, segunda época de La Saeta. Periódico Semanal de Literatura, Política y Costumbres fue publicado íntegramente por Juan de Arona, nombre que es uno de los veinte seudónimos registrados, hasta el momento, con los que Pedro Paz Soldán y Unanue muestra su quehacer intelectual ${ }^{4}$. Además de este seudónimo ${ }^{5}$, en el periódico podemos encontrar otros como Jenaro Vanda, Juan Sin Tierra, Críspulo Mor-Diente, Evandro Jana, Pipus, Ajenor Vanda, ¡Un Berufen!, Giovanni Senzo Terra e Iván Radeanof. Y es que la ausencia de colaboradores en el periódico se debió a que Arona tenía la férrea convicción de que en nuestro país las empresas en las que participa más de una persona están destinadas al fracaso. Así lo manifiesta Arona en el prospecto del semanario:

El presente semanario como el anterior [La Saeta] será propulsado por una sola mano; único medio de que una empresa nacional se logre. El espíritu de asociación, con todo lo que se le decanta y exagera, fracasa aquí como todo lo grande y bueno que se introduce de fuera. La unión es aquí la debilidad y el desbarajuste. Un peruano solo podría realizar los doce trabajos de Hércules, doce peruanos juntos no hacen la obra de una pulga ${ }^{6}$.

El periódico apareció el 17 de octubre de 1891, y se constituyó como un texto aleccionador: «El Chispazo es la continuación de La Saeta sin más diferencia que, aleccionado por los 22 años transcurridos, se ocupará tanto de política, cuanto no lo hizo aquella, pretendiendo introducir una imposible reforma en las costumbres del país» ${ }^{7}$.

Este proyecto reformista tenía como sustento ético el compromiso con una verdad justa, es decir, con aquella que fuese provechosa para la sociedad en cuanto respete el ámbito privado y se aleje del escándalo público. Agreguémosle a ello la voluntad del periódico por forjarse un espacio propio como medio de información, más allá del enfrentamiento con otros diarios (El Comercio, La Opinión Nacional y El Perú llustrado). Alcanzó los 87 números y llegó a su fin el 17 de junio de 1893 por tener una política de

3 Para una biografía actualizada del autor, consúltese «Juan de Arona, el censor de la República», estudio preliminar que realiza Fernán Altuve-Febres en su libro Antología de Pedro Paz Soldán y Unanue, Juan de Arona (Lima, 2005).

4 Tauro del Pino 1993.

5 El seudónimo de Juan de Arona, aparte de aparecer en las secciones «Literatura» y «Folletín», es utilizado para firmar los textos poéticos.

6 Nro. 1: 1.

7 Nro. 1: 1. El énfasis es nuestro. 
oposición al gobierno de Remigio Morales Bermúdez, quien continuó con la política represiva de Cáceres ${ }^{8}$.

El Chispazo salía cada sábado por la tarde, en un formato de $34 \times 24$ $\mathrm{cm}$, y su volumen podía variar entre cuatro y ocho páginas en función de la publicidad y de la sección «Folletín». Su precio era de diez centavos; la suscripción mensual costaba cincuenta centavos y la suscripción bimensual por diez números costaba un sol.

En lo que concierne a su corpus textual, el periódico en ocasiones incluía una caricatura de carácter político, en la que se atacaba, por ejemplo, la desigualdad social ${ }^{9}$ o el régimen autoritario ejercido por las fuerzas militares de Cáceres ${ }^{10}$. De este modo se reforzaban las ideas propuestas en los textos escritos. Entre los responsables de los gráficos figuran B. Garay, autor del retrato de Arona que aparece en la tapa del primer tomo, y Chambon, creador de la caricatura «Legación de Chile» ${ }^{11}$. Obviamente, los números que traían consigo la caricatura tenían un precio mayor: veinte centavos.

Por otra parte, El Chispazo no tenía una estructura fija; podía variar sus secciones de un número a otro. Empero, podemos mencionar tres secciones inamovibles: «Chispazos», «El chispazo» $y$ «Espinas de tuna». "Chispazos» está compuesto por poemas breves de carácter crítico, que oscilan entre lo jocoso y la reflexión seria. En esta sección aparecen textos como «A quema ropa»:

Tuyo soy, tu mano anhelo, súbita pasión me inflama.

¿Cómo te llamas? - Consuelo;

Ay hija, es poco con... suelo

¡fueras si quiera con... cama! ${ }^{12}$

O este otro titulado «Denominación de sexos»:

Es una necesidad

que el nombre de masculino

se aplique a la otra mitad,

8 Jorge Basadre (1939: 540) ha registrado la censura del periódico de la siguiente manera: «Pero la oposición crecía, adoptando, sobre todo, la forma de pequeños periódicos, muy buscados y celebrados por el público: La Cachiporra, La Tunda, El Chispazo y otros. Diversas fueron las medidas adoptadas contra los redactores y editores de estos periódicos, hasta que el gobierno acabó por suprimirlos con un decreto que prohibía la publicación de más de treinta hojas llamadas "eventuales". Al mismo tiempo, el gobierno revivió el reglamento sobre la moralidad pública expedida en 1877 que, en la parte relativa a la prensa, copiaba lo dispuesto en el reglamento de 1839».

9 Véase «Ciudad de desamparados y gobierno de amparados» (nro. 18).

10 Véase «Un sueño» (nro. 22) y «La toma del mando» (nro. 23).

11 Nro. 9.

12 Nro. 6: 1 
porque junto al femenino

nuestro sexo en realidad

viene a ser menosculino ${ }^{13}$

Los poemas son firmados por Juan Sin Tierra ${ }^{14}$. «El chispazo» es la nota principal del periódico. El tema, fundamentalmente, alude a los acontecimientos políticos contemporáneos; Arona puede ocuparse del proyecto de Ley de Inmigración discutido en el Senado ${ }^{15}$, al igual que de eventos oficiales como la inauguración del observatorio meteorológico Unanue ${ }^{16}$. A veces se publica más de una nota en esta sección. «Espinas de tuna» es la sección más extensa del periódico, pues ocupa en ocasiones dos o tres carillas. Está conformada por una serie de reflexiones que destacan por su concisión. En ellas asistimos a la representación de los dos blancos preferidos de Arona: la sociedad en crisis y el orden político degradado. Lima se ha convertido en una ciudad en la cual las condiciones de vida se han deteriorado considerablemente; Arona se pronuncia sobre el particular con imágenes que nos muestran a una Lima invadida por la frustración y la amargura: "La menos lastimosa entre las miserias de Lima es la de los pordioseros» ${ }^{17}$; «Un hombre dándole de trompadas a un colchón: esa es la lucha por la existencia en Lima» ${ }^{18}$.

Ahora, la sanción del orden político degradado se centra, principalmente, en esas gestiones autoritarias de las que es presa el país, y que solo determinan una ruptura social en la que el poder niega toda posibilidad de diálogo con la población: «Nuestras autoridades toman por la primera y única de sus atribuciones la que no es, si no la última, la que algún día no existirá, la de mandar» ${ }^{19}$.

Sobre estos ejes temáticos, Fernán Altuve-Febres ${ }^{20}$ ha tenido una perspectiva distinta, pues resalta de Arona esa actitud con la que censura el ocio generalizado y la retórica vacía de la clase política: «Arona observaba que la sequía de hombres de trabajo contrastaba con el desborde verbal de los hombres públicos, lo cual era una muestra clara de la demagogia, de la inconstancia y de la inmadurez política de los peruanos». Quien firma «Espinas de tuna» es Críspulo Mor-Diente.

\footnotetext{
13 Nro. 63: 313.

14 Alberto Tauro del Pino señala que el apelativo «refleja una amarga circunstancia biográfica, en cuanto su uso siguió a la pérdida de la hacienda "Arona" en un litigio» (1993: 104).

15 Nro. 44: 161-162. Recordemos que El Chispazo aparece el mismo año en el que Arona publica su estudio sobre la inmigración en el Perú.

16 Nro. 43: 153.

17 Nro. 3: 3.

18 Nro. 38: 116.

19 Nro. 2: 4

20 Altuve-Febres 2005: 18.
} 
Entre las otras secciones que conforman el periódico se encuentran «Variedades», en donde se publican artículos de costumbres, acertijos, charadas, entre otros textos menores, $y$ «Letreros inortográficos», en donde se hace mención directa, con datos concretos, de las faltas ortográficas que «contaminan» las calles de la ciudad. Por supuesto que Arona no pierde la oportunidad de mofarse de aquellos errores, ridiculizando también a los despistados que los cometieron:

Calle de Copacabana, 129 - «Esquina de la Perichola»— No, mi buen bachicha; no es Perichola sino Perricholi. Por lo menos la doble rr no debe faltar ${ }^{21}$.

Carabaya 140 — «Se pican bovos»— Probablemente es Ud. el primer bobo de Lima, a quien se le ocurre escribir bovos con v, exponiéndose a que proteste $\mathrm{D}$. Juan Bove ${ }^{22}$.

En El Chispazo Juan de Arona publica dos de sus obras principales. En la sección «Literatura» publica su Diccionario de peruanismos y en la sección «Folletín», Memorias de un viajero peruano.

En cuanto a la publicidad, el periódico recibe apoyo recién a partir del nro. 16. Se exponen avisos sobre seguros de vida, dentistas, agentes de aduana, boticas, empresas de vino, cigarrerías, etc. Entre todos ellos destaca, por estar a página completa y con gráficos, el aviso constante de una compañía inglesa con la que se cierran las ediciones: «Bowes, - Scout, y Westem. Lima - Londres. Ingenieros, constructores e importadores. Fabricantes de toda clase de maquinaria para minería y completas instalaciones para azúcar, algodón, luz eléctrica, ferrocarriles...».

Al final de la publicación se acostumbraba colocar un aviso que hacía referencia a los lugares de venta y, por lo general, aparecían las direcciones o los nombres de los establecimientos que ofrecían sus productos o servicios en el periódico:

El Chispazo aparece todo los sábados por la tarde. Lugares de venta y suscrición: Librería de Colville, Plateros de San Pedro; cigarrería de Chávez Portal de Escribanos, 130, en la Botoneros, 156 B, y en la imprenta de su publicación, en donde serán atendidas las reclamaciones

En Chorrillos, en la oficina de la Estación.

En el Barranco, en la Botica.

En el Callao, librería de Newton.

En Chicla, D. Antonio Cabieses. 
Correspondencia y canjes: dirigirse a P. Paz-Soldán y Unanue, Recoleta, 279.

Colecciones y números atrasados, en la Administración, Recoleta, 279, y en la imprenta de su publicación.

Es importante anotar que la distribución del periódico no se limitaba a la capital. La sección «Correspondencia particular de El Chispazo» funciona como un espacio de comunicación en el que Arona responde las cartas de quienes solicitan el periódico, que en su gran mayoría son personas de provincia: Puno, Arequipa, Cerro de Pasco, Cusco, Huaraz, Pacasmayo, Chanchamayo, Huacho, Chincha y Mollendo son algunos de los lugares hacia donde escribe Arona. Por lo general, la sección detalla el número de ejemplares remitidos, el dinero adeudado y la forma de pago, aunque en ocasiones también es utilizada para dar cuenta, no sin ironía, del atraso en la cancelación de un envío:

M. T. M. - Casapalca.- En su apreciada de antes de ayer me dice U. que por correo anterior me remitió veinte soles plata efectiva por cuenta de recibos cobrados, por conducto del amigo señor Andrés Cobos. Aún no he visto ni los soles ni al amigo. Oportunamente le indiqué a U. que se dejara de personas seguras y que remitiera con papeleta por la Empresa del Trasandino, como lo hacía el anterior agente. U. me contestó «que temía que fuera muy caro». Más caro sale ahora por las molestias que me impone ${ }^{23}$.

Hemos mencionado el carácter dinámico de El Chispazo en cuanto a su estructura. «En los trenes» tiene como autor a Jenaro Vanda y aparece en una columna titulada «Plagas de Lima». No es muy frecuente la presencia de este espacio en el periódico. A grandes rasgos, se trata de un espacio en donde se rechazan aquellas costumbres que Juan de Arona concibe como el resultado del problema educativo que afronta la República: la holgazanería, la ausencia de hábito lector, la impertinencia de los desconocidos, la falta de cordura al hablar y la fuerte inclinación por las expresiones artísticas populares ${ }^{24}$.

\section{2. "En los trenes»: un malcriado a bordo de la modernidad}

«En los trenes» nos narra la historia de un hombre de modales refinados que, al viajar en tren, es abordado por un sujeto afrodescendiente, a pesar de que intenta evitarlo fingiendo leer y pagando el pasaje de un niño con el propósito de aparentar, ante el inoportuno, que está acompañado. 
Todo es inútil, y nuestro personaje tiene que soportar las costumbres de su compañero de viaje. Y más aún, hasta después de llegar a la estación. Por ello, el relato termina con la determinación del hombre de viajar en segunda clase, sin importarle lo que ello significaba para su distinción, todo con tal de no ser molestado.

En el relato asistimos al (des)encuentro de dos estructuras mentales en medio de un espacio público sin restricciones, como lo fueron los trenes en el periodo ${ }^{25}$. Nos encontramos ante la representación de sujetos determinados por los procesos sociales decimonónicos ${ }^{26}$. Por un lado, tenemos al burgués conservador, y por el otro, al individuo subalterno poseedor de una ideología liberal.

Nuestro personaje manifiesta un comportamiento moderado, vive de acuerdo con las normas. Contrasta con la personalidad del sujeto subalterno, quien se distingue por sus actitudes groseras, pues se dice que «él no aguantaba las etiquetas monárquicas de la vieja Uropa ${ }^{27}$. Esta referencia a Europa se explica a partir de la influencia ejercida por Inglaterra y Francia en los países latinoamericanos a fines del XIX, que se constituyen como los modelos culturales a seguir para las nuevas burguesías. En ese sentido, el estilo de vida de esta clase social se identifica por su cosmopolitismo.

Ahora, el cosmopolitismo rechazado por el afrodescendiente es para el sujeto burgués signo de superioridad. Podríamos decir que «En los trenes» es un texto en el que los personajes están ubicados de acuerdo con una perspectiva vertical de la sociedad. El comportamiento educado del burgués contrasta con el de su acompañante, quien definitivamente no sintoniza con su rango social. José L. Romero se expresa como sigue sobre el particular:

La preocupación fundamental de las nuevas burguesías latinoamericanas - por lo demás, como las de gran parte del mundo- fue ensayar y consagrar finalmente un estilo de vida que expresara inequívocamente su condición de clase superior en la pirámide social a través de claros signos reveladores de su riqueza. Pero no solamente mediante la actitud primaria de exhibir posesión de bienes, sino sobre todo a

25 Fanni Muñoz (2001: 105) anota que «los nuevos medios de transporte posibilitaron una mejor comunicación entre el centro de la ciudad y las nuevas zonas de crecimiento, lo cual favoreció el uso de los espacios públicos».

26 Alberto Varillas ubica a Pedro Paz Soldán y Unanue dentro de la sexta generación de escritores del XIX, que es conformada por todos los nacidos de 1837 a 1851 . Como contexto sociocultural a sus obras, Varillas anota la pugna entre conservadores y liberales, el ingreso de las doctrinas positivistas al Perú y la importancia que se brinda a la educación nacional (Varillas 1992: 240).

27 Nro. 57: 267. 
través de un comportamiento sofisticadamente ostentoso. Por esa vía se buscaba dignificar a las personas y a las familias, y obtener el reconocimiento de una superioridad $[. . .]^{28}$.

Alberto Varillas ${ }^{29}$ ha señalado que la pugna entre conservadores y liberales en el siglo XIX se acentúa al abordarse temas religiosos y educacionales. En efecto, en función de la educación de los personajes, el texto de Arona marca los límites entre el viajero molestado, quien representa la tendencia conservadora en la que el orden rige las relaciones sociales, y el sujeto del sector popular, representado con significantes negativos («verdugo», «malcriados», «ganapanes», «importuno»; también se produce su animalización: «buitre», «tábano», «moscón»). A través de un proceso de alteridad el individuo de la periferia juzga al burgués por seguir el paradigma europeo, y este juzga al otro tildándolo de «grosero liberalote».

La relación de alteridad entre ambos personajes nos aproxima a las formas de apropiación del fenómeno de la modernidad por parte de estos miembros de sectores sociales diferenciados ${ }^{30}$ : la modernidad para el burgués es entendida en términos de selectividad y de distinción; en cambio, para el sujeto afrodescendiente la modernidad es sinónimo de integración.

En esta dirección, el proyecto estético-ideológico de «En los trenes» nos propone a la figura del burgués como sujeto modélico para la sociedad; se trata de un proyecto modernizador en el que el orden predomina sobre la libertad social. De esta manera, en el texto se efectúa la sanción de las costumbres tradicionales en pos de una modernización cultural de la sociedad, intención promovida por el Estado y por grupos de profesionales e intelectuales de la época ${ }^{31}$. En el sujeto burgués se concentra una nueva moral en la que la disciplina, el progreso, la moderación, la higiene y la sensibilidad estética (nuestro personaje es «excéntrico» y «caviloso») son los valores adecuados con los cuales superar el estado de barbarie en el que se vive y encaminarse así hacia el objetivo de construir una sociedad verdaderamente moderna.

Si bien es cierto que la prensa decimonónica fue el espacio alternativo - después de la universidad - en donde se desarrollaron las posturas progresistas del periodo ${ }^{32}$, cabe preguntarnos en qué medida se presenta ese afán de modernización, ya que periódicos como El Chispazo asumen 
esa empresa como algo imposible. Pensamos que en el fondo se trata de un proyecto ambivalente, pues al discurso de élite modernizadora ${ }^{33}$ subyace el pesimismo por una sociedad en crisis y sin posibilidad de cambios; se determina así una concepción vertical de la sociedad frente a la heterogeneidad cultural del país.

Finalmente, podemos señalar que el relato objeto de estudio nos sitúa frente a esa experiencia inconclusa que fue nuestra modernidad, puesto que si, por un lado, el espacio en el que se desarrolla la diégesis es un tren, signo del progreso junto a los vapores y a los avances de la ciencia, por el otro nos aproxima a un orden social en el que predomina la desigualdad y la exclusión, lo que atenta en contra de los principios republicanos ${ }^{34}$. Esta visión del mundo en la que no se admite al otro se inscribe dentro del discurso propio del sujeto esclavista, categoría propuesta por Marcel Velázquez ${ }^{35}$ para el estudio de la construcción cultural que del afrodescendiente realiza la élite letrada decimonónica. El discurso del sujeto esclavista presente en nuestro relato debe entenderse en el marco del racialismo científico finisecular, el cual concebía a los afrodescendientes a partir de una óptica esencialista, culpándolos de la degeneración del orden social. La legitimación de las prácticas racistas llevada a cabo por la élite sobre la base de argumentos científicos sirvió como un mecanismo de resistencia ante el caos social producido por la interiorización generalizada de las ideas liberales y democráticas de igualdad formal, lo cual determinó un proyecto político moderno solo en apariencia, pues prevalece esa mirada colonial que enclaustra al otro en la inmoralidad y la perversión, sin ninguna posibilidad de contacto ni superación social.

33 Muñoz 2001: 18.

34 Como señala Basadre, «la idea de ir al fomento o desarrollo nacional a través de las vías de comunicación no estuvo acompañada, como podría estarlo a mediados del siglo XX, por preocupaciones de orden social, orientadas a buscar un alza en del [sic] nivel de vida, un aumento de la productividad» (2005 t. 10: 84).

35 Velázquez 2005: 78. 


\section{REFERENCIAS BIBLIOGRÁFICAS}

ÁGUILA, Alicia del (1997). Callejones y mansiones: Espacios de opinión pública y redes sociales y políticas de la Lima del 900. Lima: Fondo Editorial de la Pontificia Universidad Católica del Perú.

ALTUVE-FEBRES, Fernán (2005). Antología de Pedro Paz Soldán y Unanue, Juan de Arona. Lima: Quinto Reino.

ARONA, Juan de (1892, 12 de noviembre). «En los trenes». En El Chispazo, segunda época de La Saeta. Periódico Semanal de Literatura, Política y Costumbres, año II, nro. 57, pp. 266-267.

BASADRE, Jorge (1939). Historia de la República 1822-1899. Lima: Librería e Imprenta Gil.

Lima: Orbis Ventures.

(2005). Historia de la República 1822-1933 [tomo 10].

MUÑOZ, Fanni (2001). Diversiones públicas en Lima, 1890-1920. La experiencia de la modernidad. Lima: Red para el Desarrollo de las Ciencias Sociales en el Perú.

ROMERO, Emilia (1966). Diccionario manual de literatura peruana y materias afines. Lima: Universidad Nacional Mayor de San Marcos.

ROMERO, José L. (1976). Latinoamérica: las ciudades y las ideas. México D. F.: Siglo XXI Editores.

TAURO DEL PINO, Alberto (1993). Catálogo de seudónimos peruanos. Lima: Ariel-Comunicaciones para la Cultura.

VARILLAS, Alberto (1992). La literatura del siglo XIX. Periodificación y caracterización. Lima: Fondo Editorial de la Pontificia Universidad Católica del Perú.

VELÁZQUEZ, Marcel (2005). Las máscaras de la representación. El sujeto esclavista y las rutas del racismo en el Perú. Lima: Universidad Nacional Mayor de San Marcos. 


\section{En los trenes ${ }^{36}$}

\section{Jenaro Vanda}

Siempre que veo a un hombrecito que va apurado $a^{37}$ tomar el tren, me lleno de consternación.

-A la idea de que no lo alcance -me interrumpe mi limeñito lector, con la sempiterna pretensión, que tanto le fomentan de que él es mu vivo.

No, señor; mi humanismo va mucho más lejos, y mi pregunta es:

—infeliz! ¿Quién será tu verdugo durante el trayecto?

Porque, dados los malditos carros americanos, como se les llama, y la vida familiar que aquí se lleva, el trayecto se convierte en un acto de sociedad entre 60 personas, en el que todos se molestan, hastían y manosean.

Allí salta forzosamente el verdugo, que al ver a un pobre pasajero solitario arrinconado en su asiento, se abalanza sobre él, se arrellana a su lado y comienza a aguijonearlo hasta el último paradero.

Un amigo mío, excéntrico célibe, se valía de todos los medios para librarse de esta compañía impuesta que ya sabía le esperaba en los trenes.

Se llevaba un paquete de viejos periódicos del anteaño pasado, se fingía abrumado en su lectura, tirándose el sombrero hasta las narices, y esparciendo algunos números sueltos en el asiento de al lado.

Nada ahuyentaba al buitre, que desde el otro extremo del coche salón lo divisaba, y acto continuo ${ }^{38}$ se venía sobre él desarrollando una fuerza como de 80 pollinos $^{39}$.

$Y$ se le pegaba.

Ideó después hacerse acompañar de alguno de sus sobrinitos, pasando por el sacrificio de pagar pasaje y medio.

Por mucho tiempo esta débil barrera contuvo aun a los más impudentes, y nuestro excéntrico ${ }^{40}$ célibe se pagaba de su gusto de ser enteramente dueño de su persona en todo el tránsito ferrocarrilero.

Hasta que llegó la plaga N. 1.

Un individuo que a título de muy liberal, como él decía, se creía con facultades, lo mismo que otra sarta de ganapanes de esta ciudad de

36 Texto recogido de El Chispazo, segunda época de La Saeta. Periódico Semanal de Literatura, Política y Costumbres de Juan de Arona. Lima, sábado 12 de noviembre de 1892. Año II, nro. 57, pp. 266-267.

37 En el texto original, la preposición $a$ aparece tildada.

38 En el texto original, aparece contínuo.

39 Pollino: asno joven y cerril. Hijo o cría de aves o cuadrúpedos. Figurativamente, alude a la persona simple, ignorante o ruda (Diccionario de la lengua española, versión online).

40 En el texto original, excéntrico está escrito sin tilde. 
malcriados, a abordar, manosear e interrogar al género humano.

La víctima lo presintió antes ${ }^{41}$ de sentirlo; se tapó la cara; fingió ${ }^{42}$ que dormía, que sufría.

No le valió.

— ¡Hola! Mi amigo — le dijo el grosero liberalote dándole un gran manotón en el hombro. ¿Cómo se hace Ud. el que no ve a los amigos, no? Vaya, a este chiquito lo colocaremos acá, el viaje en compañía ${ }^{43}$ se acorta.

— Se alarga — gimió por lo bajo el abordado.

Y empezó el cruel suplicio que debía durar media hora.

El pesado huésped se estiró en el asiento de que había desalojado al niño; le metió entre las piernas a su víctima un enorme saco de noche cuadrado que traía en la mano, y como de costumbre, comenzó a imponerle sus costumbres.

—Ese ventanillo — dijo-, lo bajaremos, porque el polvo nos sofoca. (O lo alzaremos, si estaba bajo, para no asfixiarnos).

De repente exclama:

- ¿Pero qué clase de viajero es Ud.? ¡Se ha plantado Ud. en todo el lado del sol! Esto no puede ser. Vámonos al frente.

Y quieras que no, cargó con su víctima, siempre a título de muy liberal.

Él no aguantaba las etiquetas monárquicas de la vieja Uropa.

El tren se puso en marcha.

El tábano principió por limpiarse el pecho. Vino enseguida un alargar y recoger la boca cerrada, que recordaba el movimiento de la cola de la tortolita, cuando la mansa paloma va a expeler.

—Dios nos asista! — gimió la víctima, conocedor de su peis ${ }^{44}$ —; viene la baba, la estela del siglo XIX ${ }^{45}$.

41 En el texto original, antes está escrito así: ántes.

42 En el texto original, fingir aparece con $j$ en lugar de $g$.

43 En el texto original, compañía aparece sin tilde.

44 Creemos que es un error de carácter tipográfico. Debería decir país. En otras columnas del periódico, aparece peis en letras cursivas, con el propósito de asignarle un significado particular a la palabra en función del contexto del artículo en el que se inserta.

45 En El Chispazo de Juan de Arona la baba es muy representativa de las costumbres vulgares del siglo XIX. Esto resulta evidente por sus constantes menciones en artículos diversos. Por ejemplo, en el nro. 3, con fecha 31 de octubre de 1891, se publica un cuadro de costumbre firmado por Ajenor Vanda titulado «La baba», y en el cual se expresa lo siguiente: «La baba es el reguero del siglo XIX. Por donde quiera que vayas, darás con ella. En los vagones, en los trenes, en todo piso» (Juan de Arona. El Chispazo, segunda época de La Saeta. Periódico Semanal de Literatura, Política y Costumbres de Juan de Arona. Lima, sábado 31 de octubre de 1891. Año l, nro. 3, p. 30). 
Y un instante después caía a sus pies ${ }^{46}$ una enorme plasta de saliva, que el emisor refregaba inmediatamente con la suela de su ancha bota, creyendo que esto era el non plus ultra ${ }^{47}$ de la pulcritud.

- ¿Cuándo se inventarán vagones-garitas? — pensaba nuestro oprimido pasajero. ¿O un sistema celular como en la Penitenciaria?

$Y$ no iba muy descaminado.

El progreso industrial tiende a favorecer el aislamiento del hombre, libertándolo del prójimo importuno.

¡Cuando hasta en las cámaras de los vapores se han sustituido las incómodas mesas largas con mesitas de una silla!

El tren sigue avanzando y el importuno no cesa de hablar; y con lo que esfuerza la voz para dominar el ruido de la marcha, se arma una atmósfera ensordecedora, que trae medio loco a su desgraciada víctima.

De cuando en cuando se interrumpe para apostrofarlo:

—Pero ¿qué diablos tiene Ud.? ¿Está Ud. enfermo? ¿Está Ud. de mal humor?

-Estoy oyendo.

$-i$ Eh?

-Que lo estoy oyendo.

$-i$ Eh?

—iiiQue estoy oyéndolo a Ud., hombre!!!

Los médicos deberían prohibir que se conversara en los trenes en marcha, porque hay que hacer esfuerzos fatigantes de atención y de voz, para oir ${ }^{48}$ y para hacerse oír.

Con llegar a la estación, ¿nos hemos librado del moscón?

No, señor, allí viene esta pregunta:

- ¿Qué camino sigue Ud.?

-Por aquí.

-Yo también ${ }^{49}$.

—No; me he equivocado, es por acá

—Lo mismo me da; puedo acompañarlo a Ud., la buena compañía corta el camino.

46 En el texto original, aparece piés.

47 Non plus ultra: locución de origen latino con la que se alude a todo aquello que se considera lo máximo o más excelente dentro de su clase. Lo mejor.

48 La palabra oír, que se repite en este párrafo dos veces, en ambos casos aparece sin tilde. 49 En el texto original, también está escrita sin tilde. 
Nuestro caviloso viajero comenzó por renunciar a viajar en los trenes suburbanos de Lima.

Esto era insostenible.

Al fin... joh remedio heroico ${ }^{50}$, nauseabundo, denigrante, pero el único que garantizaba por completo la independencia personal en el trayecto!

Nuestro hombre decidió viajar en segunda clase, en medio ${ }^{51}$ de la mugre.

Allí gozaba de la vista del campo, de la lectura, de la meditación... Y nadie se metía con él. 